\title{
Reinventing the Rules: Emergent Gameplay for Civic Learning
}

\author{
Cristina Ampatzidou
}

\begin{abstract}
Serious games are tools that can instigate civic learning through the social interaction among players who exchange information, negotiate and deliberate during gameplay. Energy Safari is a serious board game developed to make citizens familiar with the energy transition in the province of Groningen, the Netherlands and how it translates in local and regional policies. This chapter analyses how players have collectively exploited the ambiguities in the rule set of the game to define their own rules, regarding project selection, partnerships, knowledge exchange and attitude towards the local government. These ad hoc agreements encouraged players to reflect and relate in-game situations to their real-life experiences with energy transition, leading to civic learning. In doing so, they "bend the logic" of current assumptions for the energy transition and demonstrate possibilities for positioning emergent gameplay within the design and negotiation processes of actual hackable urban and regional policymaking.
\end{abstract}

Keywords Board games $\cdot$ Energy policy game $\cdot$ Emergent gameplay Civic learning

\section{Introduction}

Within the field of urban planning and policy, games have been employed as early as the 1950s (Abt 1969; Duke 1975) and are still a popular medium, particularly in the areas of participatory and interactive policymaking (Mayer 2009; Poplin 2012). In contrast with other methods of citizen participation that are based on information and consultation, games can be appealing both to citizens and policymakers, because a major part of control is placed on the players, providing them with a sense of agency (Sweetser 2006). Games are usually conceptualized as rule-based systems, where

\footnotetext{
C. Ampatzidou ( $\bowtie)$

Department of Spatial Planning \& Environment, Faculty of Spatial Sciences, University of Groningen, Landleven 1, 9747 AD Groningen, The Netherlands

e-mail: c.ampatzidou@rug.nl 
players try to achieve given goals by overcoming set obstacles (Abt 1969; Juul 2011; Parlett 1999; Suits 1979). However, games have also always been collective activities and social experiences that allowed players to relate to one another. This social aspect adds a layer of complexity to the rule-based gameplay, which is associated with several benefits, such as improving interpersonal relations between players (Fang et al. 2016), increasing the fun aspect (Gajadhar et al. 2008) and contributing to learning (Abdul Jabbar and Felicia 2015; Dahlgren 2009; Whitton 2011).

Energy Safari is a serious board game about the energy transition in Groningen, the Netherlands. The energy transition is a large-scale structural policy change towards the increased use of renewable energy sources, the introduction of energy saving measures and the significant reduction of dependency on fossil energy (Hauff et al. 2014). As the success of the energy transition depends both on centralized policies, corporate responsibility, and on a widespread application of local energy initiatives from the side of citizens, Energy Safari can be considered as a tool for hackable city-making (Ampatzidou et al. 2015) that engages players in an open and inclusive process of addressing the nuances of energy planning and policy. The goal of Energy Safari is to make players familiar with the regional policy vision for the energy transition, with a focus on the province of Groningen and instigate interest in local energy initiatives. It aspires to achieve that in two distinct ways. First, it aims to encourage civic learning; that is, to facilitate a process of learning about the social, political and economic reality of the community (Shaffer et al. 2005) represented in local energy projects. Civic learning comprises the knowledge of institutions, ability for deliberation, and personal interest for common affairs (Raphael et al. 2010), a set of conditions deemed essential to hackable city-making. The second goal of the game is to enable collective efficacy, that is, to stimulate the capacity of the group to realize collective, as opposed to forced, goals (Sampson et al. 1997) by providing players with ideas about the variety of potential projects that can be part of decentralized energy saving and production.

Early applications of games for urban planning were influenced by systems thinking and focused mainly on modelling and simulating urban dynamics, in areas such as transportation, land use and natural resources management (Abt 1969; Duke 1975; Mayer 2009). However, following developments in planning theory, there is a reorientation in thinking of cities as systems to be designed and controlled towards cities as systems that evolve based on social processes and behaviours (Batty 2010). So even though simulation and modelling still have a strong presence in urban planning and policy games, the focus seems to be shifting towards the potential of games to create environments for negotiation, deliberation and collaboration among players (Gordon and Baldwin-Philippi 2014; Poplin 2012). The research project described in this chapter contributes to this debate by examining whether gameplay that emerges from the spontaneous social interaction among players in a co-located game setting can contribute to the instigation of civic learning. The exploitation of inexactitudes in the rule set of Energy Safari by the players, in order to define their own rules and enhance their playing experience, is framed borrowing the notion of emergent gameplay from game studies. This study analyses seventeen game sessions of Energy Safari and the ensuing debriefing conver- 
sations, that took place over a period of one month in various locations in the city of Groningen. The analysis documents emergent behaviour in the ways the players came up with new rules, and locates civic learning in the connections players made between their in-game behaviour and their real-life experiences. Finally, it reflects on the possibilities for hackable city-making, as games utilize the uncertain and unpredictable manifestations of emergent gameplay to reveal the underlying rationalities of actors and encourage them to undertake new pathways to action.

\section{Civic Learning: A Condition for Hackable City-Making}

Civic learning is a process of learning about the social, political and economic reality of the community (Shaffer et al. 2005) and is a central requirement for appreciating social responsibility, justice and personal freedom (Lee et al. 2013) and for effective and reliable participation in civic life (Raphael et al. 2012). Civic learning is a complex process that is influenced by a person's community, education and participation and requires collective reflection and trust building (Gordon and Baldwin-Philippi 2014). For Raphael et al. (2010), civic engagement is connected to three practical attitudes, which set the desired goals of civic learning: first, encouraging citizens to be familiar with the institutions and legal frameworks that orchestrate civic processes; second, fostering the cultivation of skills that allow citizens to express themselves and articulate their interests and concerns, also through tools such as petitioning, advocacy and protest; and finally, instigating a personal interest in community life and public affairs. That means that civic learning is a condition for a hackable city in that it enables citizens to understand and engage with existing institutions, perhaps encouraging them to open up their administrative processes to new ideas and frameworks. Through civic learning, citizens also develop the skills to explore new solutions and ideas on on-going urban processes and communicate them and pursue their collective interests through coordinated action and efforts that also contribute to hackable city-making.

Games are ever more considered a significant educational resource as they combine entertainment and learning (Abdul Jabbar and Felicia 2015; Boyle et al. 2012; Whitton 2011) found at the balanced amount of progressing challenges, the feedback loops and rewards offered to the players, the social interactions that develop among players and replayability (Gee 2005). Benefits associated with the use of serious games as learning technologies to improve both cognitive and social learning encompass increasing literacy on specific topics, raising awareness, developing (complex) problem-solving skills, increasing media literacy, enhancing visual thinking and spatial sense, and building networks and coalitions (Crookall 2010; Erhel and Jamet 2013; Gee 2005; Granic et al. 2014; Shaffer et al. 2005). Harteveld and Bekebrede (2011) separate between direct transfer learning, which consists of concrete, predefined and measurable objectives and open-ended learning, which is abstract and difficult to measure. Unlike in simulations and models, real people 
can discover new knowledge during the gameplay (de Caluwe et al. 2012) and can experience both direct transfer learning on the level of the game content and openended learning from the behaviours that emerge out of the social interactions of the players, while, for example, negotiating strategies, sharing knowledge or resources. Even when players play competitively, learning still happens in a cooperative way (Oertig 2010), and positive social interaction among the players during the game has also been connected to increased learning (Padilla Zea et al. 2009). Particularly, board games provide more fun and immersion (Gajadhar et al. 2008) and can improve interpersonal relationships (Fang et al. 2016) leading to trust development among players and possibilities for collaboration in contexts external to the game.

Civic learning can be achieved when players reflect on their current civic practices, conceptualize them within a wider context and are able to apply the skills they acquire through the game in the real world (Dahlgren 2009). Raphael et al. (2010) also pay attention to the transfer of knowledge from the game to the real world arguing that games can "foster civic learning when they help players to develop knowledge, skills, and dispositions that players can then apply to public matters in the world outside the game." (203). The authors have proposed a framework for understanding how games can foster civic learning, arguing for a balanced integration between content and gameplay, the linkage of ethical and expedient reasoning, and the facilitation of connections between individual actions and collective or social structures. As civic learning is a predominantly social and open-ended form of learning, turning to the social interactions between the players of a co-located game setting can offer valuable insight into how civic learning takes place.

\section{Reinventing the Rules: How Emergent Gameplay Happens}

In complexity sciences, the term "emergence" is associated with the unpredictable behaviour of dynamic systems that arises from the interaction of their parts (Casti 1997), with the whole being more than the parts (Holland 1998; Lissack 1999) and to processes of self-organization (Holland 1998; Goldstein 1999). In the context of games, emergence is used to describe the complexity of gameplay that cannot be deterministically attributed to the simplicity of the rules (Juul 2002), and for several scholars, such as Adams and Rollings (2007); Baterman and Boon (2006), even gameplay is an emergent quality of the game (Doormans 2008). Emergence is particularly important for game designers because it ensures that rules can be played out differently every time. Emergence in games can include patterns that appear because of complex programmed mechanisms within a game and the behaviour that manifests on an experiential level, when complex social relationships form between the players, during social play (Salen and Zimmerman 2004). As Jeremy Campbell 
has put it "One can describe the rules but not necessarily all the products of the rules" (Campbell 1982 cited in Salen and Zimmerman 2004, 159).

Emergence in games can happen either in the direction of narrative, as with roleplaying games, or of gameplay, as with strategy games (Sweetser 2006; Yap et al. 2015). Emergent behaviour can be implied (Vogiazou 2007; Juul 2002), as in the case of chess or even be hardcoded (Sweetser 2006) in the rules of the game, for example, by the use of algorithms that simulate actor behaviour or fluid movement in video games, but it can also manifest itself in the interactions of players with game elements (Yap et al. 2015) and with each other (Salen and Zimmerman 2004). In the last two cases, emergent gameplay also denotes the use of a game by the players in ways unintended by the designer (Sweetser 2006; Smith, n.d.), for example, in abolishing or introducing rules and creating new strategies. In this sense, emergent gameplay constitutes a form of playful reverting of the logic of the game, to make it do things it was not designed for. Rule breaking in any form is a "natural extension of the flexibility of the game structure" (Salen and Zimmerman 2004, 282). By cheating, changing the rules and improvising new ones, players subvert the meaning of the game in order to improve their playing experience. Salen and Zimmerman (2004) attribute the various attitudes of rule breaking (cheating, workarounds, spoil-sport hacking, etc.) in digital games to the anonymous and mediated nature of the gameplay and the limited physical presence of other players.

However, rule breaking, cheating and hacking also happen in board games, which are naturally co-located with a small group of players that usually know each other. In addition, the social relations among players can greatly influence their in-game choices. An obvious quality of board games is that they bring people together in the same space, around the game board. Holland (1998) used board games as an example of emergent behaviour in his definition of emergence as a whole that is more than the sum of its parts. This is because in board games, individual player agency and social interactions among players can expand the space of possibility of the game well beyond the magic circle (Salen and Zimmerman 2004), which includes the finite space of the board, objects such as tokens and the rule set. Rules in board games are usually simpler than in computer games and are always explicit, which make emergence in board games easier to study (Doormans 2008; Zagal José et al. 2006). Harteveld and Bekebrede (2011) argue that multiplayer games are process intensive and characterized by social rules. These conditions make board games a well-suited case for observing emergent gameplay and evaluate whether the emerging behaviours and social interactions between the players and the game, and among the players, contribute to civic learning.

\section{Playing with the Rules of Energy Safari}

Energy Safari was created in the framework of the JPI Urban Europe program "Playing with urban complexity: using co-located serious games to reduce the urban carbon footprint among young adults". The game was developed by a small team of urban 
planning researchers through a series of co-creation sessions with local stakeholders involved in the energy transition in Groningen. These included policymakers from the local government, researchers from urban planning, sociology, architecture and game design, members of citizen energy initiatives and employees of private utility companies. The prototype that resulted from this process of co-creation was consequently tested in a series of 17 sessions spread over the period of one month, in various locations in the city of Groningen, including a cultural space, the premises of the municipality, the university campus and the offices of private companies. The players involved in these sessions consisted of students, members of citizen energy initiatives, policymakers and city officials, researchers of various disciplines and institutions, employees of local utility companies and lay people, which were recruited using a variety of methods, such as direct invitation, social media announcements, newsletters and snowball sampling. Playing sessions were mapped using participant observation and were also audio recorded, coded and analysed. Players had to fill in a before and after survey enquiring socio-demographic data, knowledge and attitude towards the environment, energy and civic participation, player types and game preferences, gameplay and strategy and learning impact. Each session concluded with a debriefing session in the form of a focus group discussion.

Energy Safari is a six-player board game designed for a closed co-located setting and played with the support of a game master, usually a member of the research team. Players move their avatars across the board and seek to realize energy-related projects by finding partners among other players, securing permissions and providing the financing. The specific requirements to fulfil these three steps vary per project and are described in project cards that players draw from a deck depending on their position on the board (Fig. 1). Additional elements of the game include joker cards that allow players to overcome certain steps of project realization, rising energy prices and global events that take place at the end of each round, projects' contingent effects and interdependencies between neighbouring projects. The game attempts to balance competition and collaboration among players. Players need to achieve individual goals, but they need the support of their fellow players. Each realized project provides three types of revenues to the contributing players, leading to three possible winning conditions: a financial revenue in coins, a renewable energy output measured in KW points and a community output, also measured in points, that corresponds to the local social value of each project. It is in the three separate steps of realizing a project where players most intensely competed and collaborated with each other by establishing new rules and exploring the possibilities in the space afforded by the ambiguous rule set of the game. Some instances of the specific ways that emergent behaviours manifested during each step of realizing a project within the game are described in the following sections. 


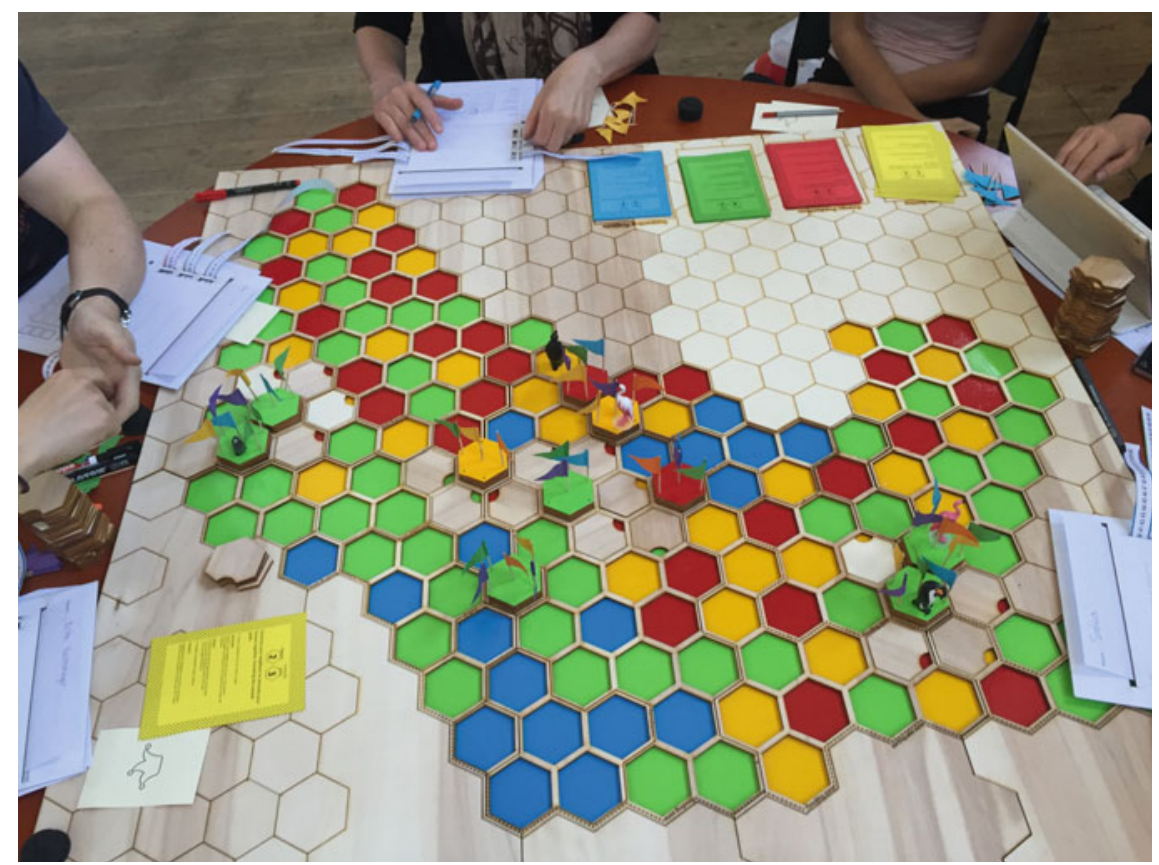

Fig. 1 Energy safari board during a gameplay session. The colourful cards describe projects. Realized projects are placed on the board, and each collaborator adds their own flag and keep track of their revenues in the board

\subsection{Project Selection}

People participate in local energy initiatives for different reasons that may include care for the environment, reduced energy bills, independence from big energy corporations, social cohesion (Boon 2012), adding local value and creating jobs (Rogers et al. 2008). As such, during the game, the selection of projects was often subject to personal experiences and ideological choices. Players often refused to participate to projects that they deemed unsustainable in real life, even when that meant that their in-game winning chances would be compromised. Upon picking a biodiesel related project card, a player involved in an existing community energy project said: "Oh! This is about biodiesel... No, I don't want to do it. I don't like biodiesel, I think it's the stupidest thing to do!" (G605-1). In several cases, players already involved in energy initiatives in the city could answer quiz questions based on their practical knowledge. "This is what we do!" (G614-2) explained to his fellow players, a player faced with a question about energy cooperatives selling energy to consumers, after answering correctly. 


\subsection{Forming Partnerships}

Each project card requests from the player to find a specific number of partners in order to realize the project. In order for another player to participate in the project, they have to invest a small amount. Should the project not succeed at a later step, this investment is lost. Should the project advance, each partner receives a one-time revenue of energy and community points and a financial return in all consequent rounds. As such, becoming somebody's partner includes a risk, but the earlier on a player invests the more profitable his investment could become in the long run.

As the exact mechanism of choosing one's partners is not specified, in some cases, players automatically adopted a first-come, first-served rule to forming partnerships. Project initiators advertised their projects and the revenues that their partners would receive, and players would chip in the requested amount. But as the number of required partners was always lower than the number of total players, several occasions of competition arose among players who wanted to participate. Sometimes players would ask the project initiator to explain in detail the project at hand, and very often they would bid their way to partnership by offering more than the requested investment amount: "If you want, I can pay two coins to join." (G614-1) Occasionally players would contest that or check with the game master if that is permitted: "Is that even allowed?" (G614-1), but most often, they would adopt this dynamic as an emergent rule and play along with negotiating the exact terms of the cooperation. In other occasions, partnerships were formed in terms of reciprocity. Players tended to include fellow players that had previously included them in their projects and exclude players that had excluded them. Collaboration based on reciprocity was stronger among players that knew each other than among people who only met during the game. A pattern that emerged in several sessions was that of excluded players punishing their fellow players by blocking the projects they were left out from: "I was not included, and I promised you were going to regret it." (G615-1). Blocking other players' moves intensified towards the end of the game, when players had a better overview of everybody's points, so blocking was used as a tool to hold back players that had collected several points and were closer to winning.

\subsection{Knowledge Exchange}

In order to secure permission for the projects, players have to roll the dice or answer a quiz question. Depending on the project, sometimes they can choose which option to use, and in rare occasions no permission is necessary but other conditions need to be met, such as paying a higher price for the project. When the choice between rolling the dice or answering a question was available, players were forced to choose between basing their project on luck or trying out their knowledge. The questioning mechanics indirectly provides players with some information about sustainability goals and the energy transition in the Netherlands. In practice, the quiz questions 
proved to be one of the most collaborative elements of the game. Despite the fact that the question was addressed to the player currently playing, in almost all sessions players, sometimes only the project partners and other times all the players, started collaborating spontaneously in trying to find the correct answer regardless of whom the question was addressed to.

Some of the joker cards featured in the game allow players to go ahead without a permit or to learn the answer to the question and move on. An additional strong element of collaboration was the fact that joker cards were often used as a common resource. When the project initiator did not have a card that would allow her to overcome the question, other players would offer their cards, to the advantage of the group.

Player groups were mixed and included both people unfamiliar with and people involved in energy initiatives, as well as researchers and employees of the local government. That meant that some players were more knowledgeable than others in answering the questions, and other players would expect them to be able to answer the quiz questions correctly and wanted to use this to their advantage. As a player said to another: "OK then let's go for answering a question, because you work for the municipality, so you should know." (G605-2). From time to time, these expectations also led to interesting negotiations, where players would exchange coins, joker cards or the promise of priority inclusion in future projects. Often, knowledgeable players would avoid showing off and would prefer to either provide some clues or help players in other ways. On one occasion, a player not participating in a project preferred to sacrifice a joker card that would allow her fellow players to bypass the question, instead of providing the answer.

\subsection{Bribing}

A bribing mechanic also exists in selected projects. Players can choose to pay a few coins extra to overcome a disadvantageous chance to get a permit by rolling the dice. However, when they opt for a bribe they lose their community points revenue. This forced players to adopt an ethical attitude and decide whether they would engage in bribing and advance easier in the game or whether they would take the risk of proceeding with unfavourable chances of success. The following excerpt (G605-2), which brings together almost every manifested attitude towards bribing, demonstrates that some players self-imposed a rule of not bribing and not participating in projects that would involve bribing, while others agreed on the spot that bribing was not only accepted but even essential in advancing, and others went as far as to withdraw their participation from projects whose owner was not willing to be corrupted:

[Upon hearing that the project conditions allow bribing]

Player1: What? What? no... I 'm out obviously!

Player2: If the project leader wants to corrupt, I ' $m$ in!

Player1: You are so corrupt all of you! 


\section{[...]}

Player3: So if I throw the dice, you are all out?

Player2: I 'm out. If you roll, maybe there is no project... So you have to be corrupt!

\subsection{Attitude Towards Local Government}

The municipality or the province is most often the institution that provides the permits for the projects to go on. This reference to a real institution prompted players to share their personal experiences from the difficulties they had to face in trying to realize their own energy projects in real life, and to express their views on the role of these institutions in facilitating or impeding local initiatives, as well as on broader issues of policymaking. Some players referred to citizen initiatives being expensive to engage in because so much time is wasted in negotiations with local institutions, while others lamented their own difficulties in securing permissions and praised the game for representing them realistically: "It's too realistic!" (G605-1). Another a player said characteristically: "The permit is really the most difficult part of all. It's always the municipality, isn't it?" (G605-2). In another case, a question about the intended reduction of $\mathrm{CO}_{2}$ emissions by the municipality triggered a long debate on the goals of the local government which were perceived as unrealistic: "Yeah, that's ridiculous, but it speaks about how the municipality thinks. That they can save so much just by energy saving." (G614-2). The conversation ensued with players commenting on the dependency on gas, the existing sources of electricity and potential solutions based on their recent readings.

\section{Civic Learning Through Emergent Gameplay?}

Mapping the emergent attitudes and interactions that develop during gameplay is a necessary step to identify any form of social or collective learning (Dörner et al. 2016; Medema et al. 2016; Wendel and Konert 2016), such as civic learning. In order to transform the gaming experience into a learning experience for the players, both individual and as a group, reflection, feedback and debriefing are crucial (Crookall 2010; de Caluwe et al. 2012; Harteveld and Bekebrede 2011; Lederman 1992). Thus, the debriefing sessions allowed the players to revisit their in-game actions and behaviours and link what is represented in the game with their real-life experiences (Garris et al. 2002). From changing and inventing new rules to share their reallife experiences and debating their opinions on current matters, civic learning has manifested in different degrees in all three aspects defined by Raphael et al. (2010). 


\subsection{Bringing the Energy Transition One Step Closer}

In terms of encouraging players to understand and engage with the institutions involved in the energy transition, the participation of people with actual involvement in energy initiatives, energy policy and corporate pilot projects in the field of green energy contributed significantly to conveying both direct knowledge and a sense of vicinity to the stakeholders actually involved in this process. De Caluwe et al. 2012 assert that it is wise to include participants with relevant real-life experience in research-oriented games as these players bring their knowledge to the game and enhance realism. In the case of Energy Safari, the players with practical experience in the field of the energy transition were crucial in connecting the emergent gameplay to the topic of the game. They did this on one hand by bringing in their content-related knowledge and on the other hand by describing their real-life experiences to the other players, unwittingly keeping the discussion focused on the topic of the game.

The project cards and the knowledge questions played the role of conveying information related to the institutions and stakeholders involved in the energy transition, policy sustainability goals and existing projects and technologies. The clear structure of the project cards made the process of getting involved in a project more accessible to players with no experience in energy projects. Players with more experience, sometimes contested this simplicity but in doing so, they had to explain to other players the actual complexities that these projects involve, also indirectly contributing to building institutional capacity. Finally, the differences in players' attitudes towards bribing show that for some people, the game functioned as a mirror of their reality and for others, it represented a magic circle within which they could adopt behaviours that they would not adopt in real life. Games are considered safe environments for testing out difficult scenarios (Dörner 1996) and as the players' diverse reactions to bribing imply, in the context of a game, players feel safe in exercising behaviours that would be considered unacceptable or socially deviant outside the magic circle. In addition, this particular mechanic triggered several discussions on the actual existence of bribing and corruption in various levels of local government.

\subsection{Negotiation, Deliberation and Collaboration}

The second condition for civic learning according to Raphael et al. (2010) is the ability of citizens to articulate and claim their interests. Within the gameplay of Energy Safari, this was expressed both in the motivation behind selecting one project over another, in the ways players pitched their projects to other players to find partners and in how they handled cooperation and knowledge sharing. Some players chose their projects based on what was most beneficial within the game world. Others based their decisions on their actual ethical or ideological convictions in their decisionmaking, particularly concerning the selection of projects to initiate or invest in. As in actual planning processes, players had to negotiate with each other and find a balance 
between their individual and collective interests. This level of interaction emerged by the setting and the attitude of the players. With regards to collaborating with one another, the game did not prescribe exactly how partners should be selected, so players invented a variety of rules, namely rules of speed (the fastest one to chip in is selected), rules of reciprocity (players exchanging partnership in each other's projects) and rules or bidding (including the players with the highest bid). Each of these rules privileges a certain value of partnering. The first-come, firstserved rule was perceived as the fairest because it did not discriminate the players' attitudes during the game, whereas the partnerships based on the highest bid were disproportionately in favour of the individual gain of the project initiator. Reciprocity rules were based on acknowledging other players' in-game behaviour and rewarding or punishing it.

Apart from serving a direct transfer of information, the questions also triggered intense collaborative behaviours with regards to knowledge sharing and building upon the information provided by the question cards. The game designers expected that the player leading the project would answer the questions, but this did not occur in any single occasion. On the contrary, several new rules came to effect with regards to knowledge sharing among players. Firstly, there was a rule of collaboration among project partners based on dialogue and negotiations. Secondly, when consensus about the correct answer could not be reached, players would resort to voting for the correct answer. Finally, players would share joker cards among partners to the collective benefit of the project.

\subsection{Reflecting on Community Dynamics}

Participants to games, particularly ones for research, come to a game with the expectation to learn (de Caluwe et al. 2012). During the debriefing, most players admitted to have learned something on two levels: directly from the questions and indirectly from the gameplay about regional energy planning more broadly. Additionally, several players reported that they were inspired by the game to learn more about the energy transition in Groningen, while others mentioned that the main lesson they took out of the game was the complexity and interdependency of energy projects on a regional scale. Others focused on the necessity of cooperation in order to realize projects and win the game, a metaphor for a condition where a collective goal can lead to individual gain. This reflection also offers important indicators of the values that players assign to the different aspects of gaming, both content-wise and in terms of rules and interactions. During the debriefing, players were asked among others whether they were consciously following a strategy and whether they perceived the game as collaborative or competitive. Several players reported that they were just trying to get involved in as many projects as possible, without a real strategy and played rather individualistically. There was, however, a general agreement that in real-life contexts, people are also often willing to cooperate only for their personal benefit and not because they are intrinsically motivated. 


\section{Conclusion}

Yap et al. (2015) argue for the potential of intentionally and sufficiently ambiguous game design to encourage players to construct part of the game experience themselves, outside of the hardcoded rules of the game. In the case of Energy Safari, the institutional space that was left open by the loosely defined rules allowed players to device their own schemes of interaction, which increased enjoyment but also helped them reflect on their individual strategies, their position within the group and the contingencies inherent in real-life endeavours. Reflection over real-life situations consistently appeared in all groups and varied according to players' familiarity to energy-related topics. If the rule set was more strictly structured or the game master behaved more rigidly with regards to adhering to the rules, a lot of this knowledge exchange and consolidation would have been lost. Different initial conditions and rules would have led to different negotiations among players and different emerging rules. The potential of emergent gameplay does not lay with the exact outcomes of cheating, modding or inventing new rules, even when patterns become recognizable, but with its possibility to enable players to imagine new ways to appropriate, adjust, extend or improve the social, cultural and economic processes involved in the citizendriven part of the energy transition. This inquisitive attitude has been connected to the value of participatory governance and extensive accessibility to knowledge, particularly through collaborative processes (Powell 2016) and is fundamental to a process of hackable city-making.

Emergent gameplay seemed to have a significant contribution in players' enjoyment and learning by indirectly enhancing their breadth. During Energy Safari, reinventing the rules of the game made players more aware of the formal rules and facilitated their experiential civic learning, at least with regards to reflecting on their current practices and reconceptualizing them within a wider social context (Dahlgren 2009). However, a significant limitation of this study is that the ability and willingness to transfer the acquired knowledge in the real world is only based on the selfreported intentions of the players. But since most players played Energy Safari only once because of the research design, there is little reason to assume that it will have any long-lasting effects. At best, it can act as a trigger for deeper inquisition into the topic of the energy transition. Games could lead to long-lasting civic learning, when they are used in various stages throughout the planning process, during which players can discover new forms of knowledge.

Mayer (2009) argues that games can be used in policymaking and public planning because they can model the complexity of technical, physical and economic aspects of policy-related issues as well as the social and political aspects by including human input not as digital agents but as real people. This paper adds that while games can indeed incorporate the technical and physical aspects of policymaking in the hardcoded rules, player input alone can only partly account for the real intricacy of social and political features. Observing and analysing emergent behaviour during policy-related games can become productive for actual participatory policymaking, making it more open to appropriation by the participating citizens. Games create an 
environment where actors can still exchange information, while acting strategically to advance their own interests and demonstrating actual, spontaneous social interaction. Within the field of using serious games in urban planning, the study of emergent gameplay can offer indications of how similarly difficult to simulate behaviours might play out in the real world. Players bring into the game their irrationalities, assumptions and unconscious, tacit knowledge; all hard to delineate aspects that surface during the gameplay (de Caluwe et al. 2012). Through their genuine reactions and interactions, players of Energy Safari have spontaneously revealed how they regard the current energy policy as citizens. They have devised and implemented new rules in the game that make evident parameters, values and behaviours that are at play in thinking about and negotiating for a community project, such as a solar or biomass installation. Colocated games, be they analogue or digital, could potentially be used as negotiation and brainstorming tools to make urban policymaking more hackable, that is more tuned to the uncertainties and unpredictabilities of citizen input.

Acknowledgements The project "Playing with urban complexity: using co-located serious games to reduce the urban carbon footprint among young adults" is funded by the Joint Programming Initiative Urban Europe. The author's Ph.D. research is supervised by Dr. Katharina Gugerell and Prof. Gert de Roo.

\section{References}

Abdul Jabbar, Azita Ilia, and Patrick Felicia. 2015. Gameplay engagement and rearning in gamebased learning: A systematic review. Review of educational research 85 (4): 740-779.

Abt, Clark.C. 1969. Serious Games. New York: Viking Press.

Adams, Ernest, and Andrew Rollings. 2007. Fundamentals of game design. Upper Saddle River: Pearson Education Inc.

Ampatzidou, Cristina, Matthijs Bouw, Froukje van de Klundert, Michiel de Lange, and Martijn de Waal. 2015. The hackable city: A research manifesto and design toolkit. Amsterdam: Amsterdam Creative Industries Publishing.

Baterman, Chris, and Richard Boon. 2006. 21st Century game design. Boston: Charles River Media.

Batty, Michael. 2010. Complexity in city systems: Understanding evolution and design. In A planner's encounter with complexity, ed. Gert de Roo and Elisabete A. Silva, 99-122. Surrey: Ashgate.

Boon, Frank Pieter. 2012. Local is beautiful: The emergence and development of local renewable energy organisations. MA diss.: University of Utrecht.

Boyle, Elizabeth A., Thomas Connolly, Thomas Hainey, and James M. Boyle. 2012. Engagement in digital entertainment games: A systematic review. Computers in human behaviour 28: 771-780.

Campbell, Jeremy. 1982. Grammatical man: Information, entropy, language, and life. New York: Simon \& Shuster.

Casti, John L. 1997. Would-be worlds: How simulation is changing the frontiers of science. New York: Wiley.

Crookall, David. 2010. Serious games, debriefing, and simulation/gaming as a discipline. Simulation \& Gaming 41 (6): 898-920.

Dahlgren, Peter. 2009. Media and political engagement: Citizens, communication, and democracy. New York: Cambridge University Press.

de Caluwe, Leon, Jac Geurts, and Wouter Jan Kleinlugtenbelt. 2012. Gaming research in policy and organization: An assessment from the Netherlands. Simulation and Gaming 43 (5): 600-626. 
Doormans, Joris. 2008. Visualizing game dynamics and emergent gameplay. http://meaningfulplay. msu.edu/proceedings2008/mp2008_paper_40.pdf. Accessed 25 July 2018.

Dörner, Dietrich. 1996. The logic of failure: Recognizing and avoiding error in complex situations. New York: Basic Books.

Dörner, Ralf, Anna Lisa Martin-Niedecken, Mela Kocher, Tom Baranowski, Michael KickmeyerRust, Stefan Göbel, Josef Wienmeyer, and Paul Gebelein. 2016. Contributing disciplines. In Serious games. foundations, concepts and practise, ed. Ralf Dörner, Stefan Göbel, Wolfagang Effelsberg, and Josef Wiemeyer, 35-82. Switzerland: Springer International Publishing.

Duke, Richard. 1975. Metropolis: The urban systems game, vol. 3. New York: Gamed Simulations, Inc.

Erhel, Séverine, and Éric Jamet. 2013. Digital game-based learning: Impact of instructions and feedback on motivation and learning effectiveness. Computers \& Education 67: 156-167.

Fang, Yu-Min, Kuen-Meau Chen, and Yi-Jhen Huang. 2016. Emotional reactions of different interface formats: Comparing digital and traditional board games. Advances in Mechanical Engineering 8 (3): 1-8.

Gajadhar, Brian, Yvonne de Kort, and Wijnand Ijsselsteijn. 2008. Influence of social setting on player experience in digital games. In CHI'08 extended abstracts on human factors in computing systems, ed. J.A. Kientz. New York: ACM.

Garris, Rosemarie, Robert Ahlers, and James E. Driskell. 2002. Games, motivation, and learning: A research and practice model. Simulation \& Gaming 33 (4): 441-467.

Gee, James Paul. 2005. Why are videogames good for learning? Spectrum 32: 25-32.

Goldstein, Jeffrey. 1999. Emergence as a construct: History and issues. Emergence 11: 49-72.

Gordon, Eric, and Jessica Baldwin-Philippi. 2014. Playful civic learning: Enabling reflection and lateral trust in hame-based public participation. International Journal of Communication 8: 759-786.

Granic, Isabela, Adam Lobel, and Rutger C.M.E. Engels. 2014. The benefits of playing video games. American Psychologist 69 (1): 66-78.

Harteveld, Casper, and Geertje Bekebrede. 2011. Learning in single versus multiplayer games: The more the merrier? Simulation and Gaming 42 (1): 43-63.

Hauff, Jochen, Anne Bode, Dietrich Neumann, and Florian Haslauer. 2014. Global energy transitions-A comparative analysis of key countries and implications for the international energy debate. Berlin: Weltenergierat.

Holland, John H. 1998. Emergence: From chaos to order. Reading: Addison-Wesley Helix.

Juul, Jesper. 2002. The open and the closed: Games of emergence and games of progression. In Computer games and digital cultures conference proceedings, ed. Frans Mäyrä, 323-329. Tampere: Tampere University Press.

Juul, Jesper. 2011. Half-real: Video games between real rules and fictional worlds, 1st ed. Cambridge: MIT Press.

Lederman, Linda Costigan. 1992. Debriefing: Toward a systematic assessment of theory and practice. Simulation and Gaming 23 (2): 145-160.

Lee, Wing On, Kerry John Kennedy, and Magdalena Mo Ching Mok. 2013. Civic Learning and its contexts. Educational psychology 33 (3): 233-239.

Lissack, Mochael. 1999. Complexity: The science, its vocabulary, and its relation to organizations. Emergence 11: 110-125.

Mayer, Igor S. 2009. The gaming of policy and the politics of gaming: A review. Simulation and Gaming 40 (6): 825-862.

Medema, Wietske, Alison Furber, Jan Adamowski, Qiqi Zhou, and Igor Mayer. 2016. Exploring the potential impact of serious games on social learning and stakeholder collaborations for transboundary watershed management of the St. Lawrence River Basin. Water 8 (5): 175-200.

Oertig, Margaret. 2010. Debriefing in moodle: written feedback on trust and knowledge sharing in a social dilemma game. Simulation and Gaming 41 (3): 374-389.

Padilla Zea, Natalia, José Luis Gonzáles Sánchez, Francisco L. Guttiérez, Marcelino J. Cabrera, and P. Paderewski. 2009. Design of educational multiplayer videogames: A vision from collaborative learning. Advances in Engineering Software 40 (12): 1251-1260. 
Parlett, David. 1999. The oxford history of board games. Oxford: Oxford University Press.

Poplin, Alenka. 2012. Playful public participation in urban planning: A case study for online serious games. Computers, Environment and Urban Systems 36 (3): 195-206.

Powell, Allison. 2016. Hacking in the public interest: Authority, legitimacy, means and ends. New Media and Society 18 (4): 600-616.

Raphael, Chad, Christine Bachen, Kathleen-M Lynn, Jessica Baldwin Philippi, and Kristen A. McKee. 2010. Games for civic learning: A conceptual framework and agenda for research and design. Games and Culture 5 (2): 199-235.

Raphael, Chad, Christne Bachen, and Pedro F. Hernandez-Ramos. 2012. Flow and cooperative learning in civic game play. New Media and Society 14 (8): 1321-1338.

Rogers, J.C., E.A. Simmons, I. Convery, and A. Weatherall. 2008. Public perceptions of opportunitites for community based renewable energy projects. Energy policy 36 (11): 4217-4226.

Salen, Katie, and Eric Zimmerman. 2004. Rules of play. Game design fundamentals. Cambridge: MIT Press.

Sampson, Robert J., Stephen W. Raudenbush, and Felton Earls. 1997. Neighborhoods and violent crime: A multilevel study of collective efficacy. Science 277 (5328): 918-924.

Shaffer, David Willem, Kurt R. Squire, Richard Halverson, and James P. Gee. 2005. Video games and the future of learning. WCER Working Paper No 2005-4. Wisconsin: Wisconsin Center for Education Research.

Smith, Harvey. The future of game design: Moving beyond Deus Ex and other dated paradigms. Witchboy.net. http://www.witchboy.net/articles/the-future-of-game-design-movingbeyond-deus-ex-and-other-dated-paradigms/. Accessed 11 Aug 2016.

Suits, Bernard. 1979. The grasshopper: Games, life and utopia, 32014th ed. Ontario: Broadview Press.

Sweetser, Penelope. 2006. An emergent approach to game design: Development and play. $\mathrm{PhD}$ diss.: University of Queensland.

Vogiazou, Yanna. 2007. Design for emergence collaborative social play with online and locationbased media. Amsterdam: IOS Press.

Wendel, Viktor, and Johannes Konert. 2016. Multiplayer serious games. In Serious games. foundations, concepts and practise, ed. Ralf Dörner, Stefan Göbel, Wolfgang Effelsberg, and Josef Wiemeyer, 211-241. Springer International Publishing.

Whitton, Nicola. 2011. Encouraging engagement in game-based learning. International Journal of Game-based Learning 1: 75-84.

Yap, Christopher Michael, Youki Kadobayashi, and Suguru Yamaguchi. 2015. Conceptualizing player-side emergence in interactive games: Between hardcoded software and the human mind in papers please and gone home. International Journal of Gaming and Computer-Mediated Simulations 7 (3): 1-21.

Zagal José, P., Jochen Rick, and Idris His. 2006. Collaborative games: Lessons learned from board games. Simulation and Gaming 37 (1): 24-40.

Cristina Ampatzidou is a Ph.D. researcher at the University of Groningen on the topic of gaming and urban complexity in the JPI Urban Europe project 'Playing with Urban Complexity', and founder of Amateur Cities. Her research investigates the affordances of gaming for collaborative city-making and open dialogue among policy makers and citizens. She previously worked as an embedded researcher for the Amsterdam Hackable Metropolis project, a collaboration of the University of Amsterdam, the Mobile City Foundation and One Architecture. Cristina has been a collaborator of Play the City Foundation and the Architecture Film Festival of Rotterdam, a guest teacher at the TU Delft Faculty of Architecture and is a regular contributor to several architecture and urbanism magazines. http://www.cristina-ampatzidou.com. 
Open Access This chapter is licensed under the terms of the Creative Commons Attribution 4.0 International License (http://creativecommons.org/licenses/by/4.0/), which permits use, sharing, adaptation, distribution and reproduction in any medium or format, as long as you give appropriate credit to the original author(s) and the source, provide a link to the Creative Commons license and indicate if changes were made.

The images or other third party material in this chapter are included in the chapter's Creative Commons license, unless indicated otherwise in a credit line to the material. If material is not included in the chapter's Creative Commons license and your intended use is not permitted by statutory regulation or exceeds the permitted use, you will need to obtain permission directly from the copyright holder. 